\title{
Compensatory Recovery of Vagal Control of Hemodynamics after Unilateral Vagotomy
}

\author{
L. N. CHEN ${ }^{1}$, W. J. ZANG ${ }^{1,2,{ }^{*}}$, X. J. YU ${ }^{1}$, J. LIU ${ }^{3}$, D. L. LI ${ }^{1}$, \\ S.S. KONG ${ }^{1}$, J. LU ${ }^{1}$, X. L. XU ${ }^{1}$ X. J. YU , J.LIU , D. L. LI
}

${ }^{1}$ Department of Pharmacology, and ${ }^{2}$ Key Laboratory of Environment and Genes Related to Diseases, and ${ }^{3}$ Experimental Center of Functional Teaching, College of Medicine, Xi' an Jiaotong University, Xi'an, China

Received August 21, 2006

Accepted December 7, 2006

On-line available January 2, 2007

\begin{abstract}
Summary
This study investigated whether each part of the heart is evenly innervated by the left or right vagus and observed the mechanism of compensatory recovery after unilateral cervical vagotomy. HR, BP, LVSP and $\pm d p / d t$ max all decreased one week after left vagotomy, whereas only BP and -dp/dt max decreased one week after right vagotomy. Western blot analyses revealed that the expression of $M_{2}$ receptors in the left atrium and left ventricle was upregulated after subacute (1 week) left/right vagotomy. However, significantly more cholinesterase-positive nerves in LV and RV were seen one week after unilateral vagotomy compared to the sham-operated group. In addition, baroreflex sensitivity was increased after subacute right vagotomy. The decreasing effects of ACh $(0.5 \mu \mathrm{g} / \mathrm{kg})$ on LVSP and $\pm \mathrm{dp} / \mathrm{dt}$ max (but not on HR and BP) were facilitated by subacute unilateral vagotomy. Our present experiments indicate that 1) the working myocardium is innervated bilaterally by the vagus, 2) ventricular contractility is influenced more by denervation of the left than the right vagus and 3) up-regulation of $M_{2}$ muscarinic receptors in the left heart, increase of cholinergic nerves, and high baroreflex sensitivity could be involved in the mechanism of compensatory hemodynamic recovery via contralateral vagus overactivity, thereby amplifying contralateral vagal activity and decreasing cardiac contractility.
\end{abstract}

\section{Key words}

Vagotomy - Hemodynamics - Heart • Muscarinic receptor • Cholinesterase-positive nerves

\section{Corresponding author}

Dr. Wei-Jin Zang at Department of Pharmacology, College of Medicine, Xi'an Jiaotong University, Xi'an, 710061, China. Fax: 86-29-82655003. E-mail: zwj@mail.xjtu.edu.cn

\section{Introduction}

The autonomic nervous system plays an important role in the regulation of the mammalian heart, being divided into the sympathetic and parasympathetic (vagal) subsystems. It is known that all regions of the heart are innervated by sympathetic nerves, while parasympathetic (vagal) innervation of the heart is primarily present in the supraventricular tissues (Loffelholz and Pappano 1985). In working myocardia, atrial muscle is innervated by vagal efferents, but in contrast, the ventricular myocardium is only sparsely innervated by vagal efferents (Siegel et al. 1999). Parasympathetic (vagal) control of the heart atria involves modulation of chronotropic and inotropic activity, but its role in the innervation of the ventricles is still unclear (Brodde and Leineweber 2004, Dhein et al. 2001, Zang et al. 2005 a,b).

There is ample evidence that afferent innervation of the heart is lateralized in the peripheral part of the autonomic system with right-sided and leftsided autonomic pathways influencing cardiac activity in an asymmetric manner (Levy and Warner 1994). In accordance with a higher density of right-sided sympathetic and parasympathetic fibers to the pacemaker tissues of the SA node, chronotropic cardiac activity, as manifested by heart rate changes, is predominantly and more efficiently controlled by sympathetic and parasympathetic fibers running on the right side. Atrioventricular conduction (dromotropic activity) and myocardial contractility (inotropic activity) 
on the contrary, are more efficiently controlled by outflow from left-sided autonomic pathways (Wittling et al. 1998). Sampaio et al. (2003) also proposed that cardiac vagal ganglia in the rat show a topographical functional organization. However, there is evidence that some parts of the heart receive bilaterally symmetrical autonomic innervation, e.g. the AV junctional region (Neely and Urthaler 1992) and the left ventricle (Akiyama and Yamazaki 2001). It is also not clear whether each part of the heart is innervated evenly by the left and right cervical vagus.

It is generally believed that there is a compensatory change in cardiac vagal innervation after unilateral vagotomy (Lund et al. 1992). It has been shown in frogs that an intact vagus nerve can produce new synaptic connections to cardiac ganglion cells when their original synaptic input is disrupted by means of unilateral vagotomy (Courtney and Roper 1976). Electrophysiolo-gical evidence indicated that there was compensatory reinnervation of cardiac postganglionic parasympathetic neurons after transection of one of the two major vagal trunks (Courtney and Roper 1976, Roper 1976). The result in rats showed that choline acetyltransferase (CAT) activity, a neurochemical marker of parasympathetic innervation, was transiently decreased in the regions of the sinus and atrioventricular nodes within 72 hours of a unilateral vagotomy (Lund et al. 1979). Functional measurements in rabbits indicated that chronic right vagotomy, produced greater vagalmediated bradycardia at both 7 and 28 days than acute right vagotomy (Lund et al. 1992). Nevertheless, there have not been done any hemodynamic measurements on left ventricular function after partial vagus injury. Little is known about the underlying mechanisms responsible for the compensatory changes in cardiac muscarinic receptors.

For the above reasons, the purpose of this contribution is to investigate the influence of acute (4 hours) and subacute (1 week) unilateral cervical vagotomy on hemodynamic parameters (including LVDP, $+\mathrm{dp} / \mathrm{dt}$ max, etc.) and the expression of $\mathrm{M}_{2}$ muscarinic receptors in all four chambers of functioning rat myocardium. To investigate the mechanism in compensatory recovery, the baroreceptor reflex, the inhibitory effects of ACh on hemodynamics, and the distribution of cholinesterase-positive nerves in the four chambers were observed in a subacute experiment.

\section{Methods}

\section{Animals}

For this experiment, male adult Sprague-Dawley rats weighing 200-250 g (supplied by the Experimental Animal Center of Xi' an Jiaotong University, China) were used in accordance with recommended guidelines on the care and use of laboratory animals issued by the Chinese Council on Animal Research. The study was approved by the ethics committee at Xi' an Jiaotong University.

\section{Unilateral cervical vagotomy}

The experiment was divided into acute (4 hours) and subacute (1 week) studies. There were three groups in the acute experiment, including sham-operated, acute left cervical vagotomized and acute right cervical vagotomized rats. Both cervical vagal trunks were exposed for about $15 \mathrm{~mm}$ through a cervical midline incision. When the hemodynamic parameters had remained stable for $30 \mathrm{~min}$, the left or right vagus was transected in the middle of the cervical vagus trunk. The vagi were left intact in the sham-operated group and their hearts were used in the Western blot analysis. The hemodynamic changes during acute unilateral vagotomy were monitored at time 0 (control, before vagotomy), and 1, 2, 3 and 4 hours following vagotomy.

In the subacute part, the rats were divided into 3 groups (sham-operated, one week after left vagotomy, and one week after right vagotomy). The rats were first anesthetized with ether and both vagi were carefully dissected through a cervical midline incision. A $1-\mathrm{cm}$ segment of the nerve was removed, and the ends of the nerve were crushed to prevent any chance of rejoining or reapproximation of the nerve. Sham operation was performed in which vagi were isolated but not transected. After 1 week, the rats were anesthetized with $20 \%$ urethane. Through routine procedure, hemodynamic parameters were recorded after stabilization for $10 \mathrm{~min}$.

Prior to sectioning, the nerves were identified by electrical stimulation. Square pulses of $5 \mathrm{~V}$ amplitude, $1 \mathrm{~ms}$ duration, and $10 \mathrm{~Hz}$ frequency induced slowing of heart rate and $\mathrm{AV}$ conduction disturbances.

\section{Hemodynamic measurements}

The rats were anesthetized with $20 \%$ urethane (1.5 g/kg i.p.). In accordance with routine procedures, left ventricular end-systolic pressure (LVSP), left ventricular 
end-diastolic pressure (LVDP) and maximum rate of rise/descent of left ventricular pressure ( $\pm \mathrm{dp} / \mathrm{dt}$ max) were measured by a pressure transducer connected with polyethylene (PE)-50 tubing filled with heparinized saline $(20 \mathrm{U} / \mathrm{ml})$ placed in the left ventricle via the right carotid artery. The position of the tube in the ventricle was determined by typical pressure waves. The right femoral artery was cannulated for the recording of arterial blood pressure (BP), including systolic blood pressure (SBP), diastolic blood pressure (DBP) and mean blood pressure (MBP), monitored with another pressure transducer. An instantaneous beat-by-beat heart rate (HR) was measured from the lead II electrocardiogram (ECG). Signals were recorded with Chart v4.2.3 (Powerlab, AD Instruments, Australia).

Baroreflex response in subacute unilateral vagotomized rats

In the subacute animals, baroreflexes were elicited by bolus intravenous injections of phenylephrine $(5 \mu \mathrm{g} / \mathrm{kg})$ via right femoral vein and sympathetic effects on the heart were prevented by pretreatment of the animals with the $\beta$-adrenoceptor antagonist metoprolol $(1 \mathrm{mg} / \mathrm{kg}$ i.v.). Baroreflex sensitivity was calculated as the slope of the linear portion relationship of R-R interval (in ms) versus mean arterial pressure (in $\mathrm{mmHg}$ ) (AngellJames et al. 1980). The tabulated baroreceptor-induced change in heart rate was calculated as an average of at least two or more phenylephrine ramp-generated tests.

Muscarinic receptor activation in subacute unilateral vagotomized rats

In the subacute animals, muscarinic receptor activation was elicited by a bolus intravenous injection of ACh $(0.5 \mu \mathrm{g} / \mathrm{kg}$ i.v. Sigma). The time to effect was $\sim 5 \mathrm{~s}$. The hemodynamic responses were detected before and after treatment with atropine ( $1 \mathrm{mg} / \mathrm{kg}$ i.v. Sigma).

\section{Tissue preparation}

After detecting the hemodynamic parameters, the rats were sacrificed by cervical dislocation. The hearts were quickly removed and washed with phosphate buffer consisting of (in mM): $\mathrm{NaCl} 137, \mathrm{KCl} 2.7, \mathrm{Na}_{2} \mathrm{HPO}_{4} 10$, and $\mathrm{KH}_{2} \mathrm{PO}_{4} 2$ at $\mathrm{pH}$ 7.4. All four chambers (left atrium, right atrium, left ventricle, and right ventricle) of the working myocardium were separated, and immediately stored in liquid nitrogen.

\section{Western blots}

The preparations were homogenized on ice in tissue homogenization buffer containing $40 \mathrm{mM}$ Tris, $0.5 \mathrm{mM}$ EGTA, $2 \mathrm{mM}$ EDTA, $0.2 \mathrm{mM}$ PMSF, 0.32 M sucrose, $\mathrm{pH}$ 7.4. Homogenates were centrifuged for $5 \mathrm{~min}$ at $800 \mathrm{x} \mathrm{g}$ at $4{ }^{\circ} \mathrm{C}$. The upper liquid was removed and further centrifuged for $20 \mathrm{~min}$ at $15000 \mathrm{x}$ g at $4{ }^{\circ} \mathrm{C}$. The supernatant was collected and the protein concentration determined. Protein concentrations were measured using the Coomassie brilliant blue assay. The membrane proteins were suspended and stored at $-80{ }^{\circ} \mathrm{C}$ until used. $40 / 80$ micrograms of total protein from each atrial/ventricular sample was added to a loading buffer, and pipetted into separate lanes of a $10 \%$ SDS polyacrylamide gel. After polyacrylamide gel electrophoresis (PAGE), the proteins were transferred onto a polyvinylidene fluoride (PVDF) membrane, by semi-dry blotting for $2 \mathrm{~h}$. Following an overnight block at $4{ }^{\circ} \mathrm{C}$ in $5 \%$ degreasing milk powder/Tris-buffered-salineTween (TBS-T) containing $20 \mathrm{mM}$ Tris- $\mathrm{HCl}, \mathrm{pH} 7.5$, $150 \mathrm{mM} \mathrm{NaCl}$ and $0.1 \%$ Tween 20 , the membrane was incubated with a primary antibody (in $5 \%$ degreased milk powder / TBS-T) (Tayebati et al. 2004). The following antibodies were used: goat polyclonal antibody for $\mathrm{M}_{2}$ muscarinic receptors (1:500; Santa Cruz Biotechnology Inc.), rabbit anti-goat IgG AP-conjugated (1:500; Beijing Zhongshan Golden Bridge Biotechnology Co.), mouse monoclonal antibody for glyceraldehyde phosphate dehydrogenase (GAPDH) (1:5000; SinoAmerican Biotechnology Co.), and goat anti-mouse IgG AP-conjugated antibody (1:500; Sino-American Biotechnology Co.). The membranes obtained from western blotting were dyed with BCIP (5-bromo-4chloro-3-indolylphosphate) and NBT (nitroblue tetrazolium) (Amerisco Co.), thus giving two deep purple bands. Through image analysis (Biorad Co, USA), the optical density (OD) values were measured.

\section{Histological staining}

Histochemical analysis of cholinesterasepositive nerves was performed using a modification of a previously described method (Karnovsky and Roots 1964). Briefly, slides containing $20-\mu \mathrm{m}$ frozen sections were fixed in $4 \%$ polyoxymethylene for $20 \mathrm{~min}$, then incubated 4 hours at $37{ }^{\circ} \mathrm{C}$ in a medium containing: $25 \mathrm{mg}$ acetylcholine iodide, $32.5 \mathrm{ml} 0.1 \mathrm{M}$ acetate buffer, $2.5 \mathrm{ml} 0.1 \mathrm{M}$ sodium citrate, $5 \mathrm{ml} 30 \mathrm{mM} \mathrm{CuSO}_{4}, 1 \mathrm{ml}$ 
$4 \mathrm{mM}$ tetraisopropylpyrophosphoramide, $5 \mathrm{ml} 5 \mathrm{mM}$ potassium ferricyanide, and $4 \mathrm{ml}$ distilled water.

\section{Statistical analysis}

Data are expressed as means \pm S.E.M. and were analyzed using standard software (SPSS, V11.5). Western blot analysis was used to calculate the ratio of OD $\left(\mathrm{M}_{2}\right.$ receptor) / OD (GAPDH). Histochemical staining was analyzed using image analysis software (Motic Med 6, Motic China). Self control comparisons used paired Student's t test. Inter-group comparisons were performed using Student's t test and ANOVA test, as appropriate. Probability values of $\mathrm{p}<0.05$ were considered indicative of statistical significance.

\section{Results}

\section{Hemodynamic effects of acute and subacute unilateral vagotomy}

Figures $1 \mathrm{~A}$ and $1 \mathrm{~B}$ showed two examples of records obtained from the same rat where left/right vagus was sectioned acutely at five time points, before vagotomy (control) and at 1, 2, 3 and 4 h post vagotomy. Similar results were obtained in either unilateral vagotomized group. HR, BP, LVSP and $+\mathrm{dp} / \mathrm{dt}$ all increased gradually during the $4 \mathrm{~h}$ following acute left cervical vagotomy. The hemodynamic values are displayed in Figure 2. At $4 \mathrm{~h}$ after left cervical vagotomy, HR, MBP, LVSP, and $-\mathrm{dp} / \mathrm{dt} \max$ had evidently increased ( $p<0.05$ or 0.01 vs. control). Obviously, similar hemodynamic results were observed after the acute right cervical vagotomy (left part of Fig. 2).

Figure $1 \mathrm{C}$ is an example of the recording from the subacute experiment. Blood pressure (including SBP, DBP and MBP) was decreased in the rats at 1 week following unilateral (left or right) cervical vagotomy ( $p<0.05$ vs. sham-operated group). In addition, $-\mathrm{dp} / \mathrm{dt}$ max also was decreased in both groups $(p<0.05$ vs. sham). However, at 1 week following left cervical vagotomy, HR, LVSP, and dp/dt max had obviously decreased ( $p<0.05$ vs. sham). Nevertheless, there was no difference between 1 week following left cervical vagotomized and in the 1 week following right vagotomized group (right part of Fig. 2).

\section{Baroreflex sensitivity (BRS) in subacute unilateral vagotomized rats}

The baroreceptor reflex response was quantified using the slope of the line generated from the relationship between R-R interval during increases in arterial pressure in sham-operated, left vagotomized and right vagotomized rats $(0.85 \pm 0.09,1.34 \pm 0.24$ and $4.14 \pm 0.56$ $\mathrm{ms} / \mathrm{mmHg}$, respectively). A recovery in the baroreflex sensitivity could be detected following subacute right vagotomy ( $p<0.001$ vs. sham-operated group) but not after subacute left vagotomy (Fig. 3), which is in agreement with previous data obtained in rabbits (Lund $e t$ al. 1992).

The hemodynamic responses of acetylcholine in subacute unilateral vagotomized rats

Acetylcholine $\quad(0.5 \mu \mathrm{g} / \mathrm{kg} \quad$ i.v. $)$ produced inhibitory effects on the hemodynamics in the subacute rats, including $\mathrm{BP}, \mathrm{LVSP},+\mathrm{dp} / \mathrm{dt} \max$ and $-\mathrm{dp} / \mathrm{dt} \max$ $(p<0.05$ vs. control). The effects of ACh could be blocked completely by atropine (1 $\mathrm{mg} / \mathrm{kg}$ i.v.). Compared with sham-operated group, the decreasing effects of ACh on LVSP, $+\mathrm{dp} / \mathrm{dt} \max$ and $-\mathrm{dp} / \mathrm{dt}$ max but not on HR and $\mathrm{BP}$, were facilitated by subacute left or right cervical vagotomy $(\mathrm{p}<0.05)$ (Fig. 3$)$.

\section{Expression of the $M_{2}$ receptors in the four chambers of normal adult rat heart}

The expression of $\mathrm{M}_{2}$ muscarinic receptors for each of the four chambers (LA, left atria; RA, right atria; $\mathrm{LV}$, left ventricles; $\mathrm{RV}$, right ventricles) in the normal adult rat heart was determined by Western blot. We found that $\mathrm{M}_{2}$-receptors were indeed evident in the left and right ventricles, as expected, but that the density of $\mathrm{M}_{2}$ receptors in the atria was higher (up to 2 2.6-fold) than in the ventricles ( $p<0.05$ atria vs. ventricles) (Fig. 4).

\section{Expression of $M_{2}$ receptors in acute and subacute unilateral vagotomized rat heart}

The ratio of $\mathrm{OD}\left(\mathrm{M}_{2}\right.$ receptor $) / \mathrm{OD}(\mathrm{GAPDH})$ in the intact animals was used as the $100 \%$ reference point. The density of $\mathrm{M}_{2}$ muscarinic receptors was not significantly different between intact animals and the sham-operated group (Fig. 5). The left part of this figure demonstrates that the expression of $\mathrm{M}_{2}$ muscarinic receptors in rat hearts was not changed by acute vagotomy, except for the left atria of the left vagotomized rats, where $\mathrm{M}_{2}$ muscarinic receptors expression was upregulated ( $\mathrm{p}<0.05$ vs. sham-operated group). Western blot analysis in the subacute study (right part of Fig. 5) revealed that protein content of $\mathrm{M}_{2}$ muscarinic receptors in the left atrium, right atrium and left ventricle was upregulated one week after the left cervical vagotomy 


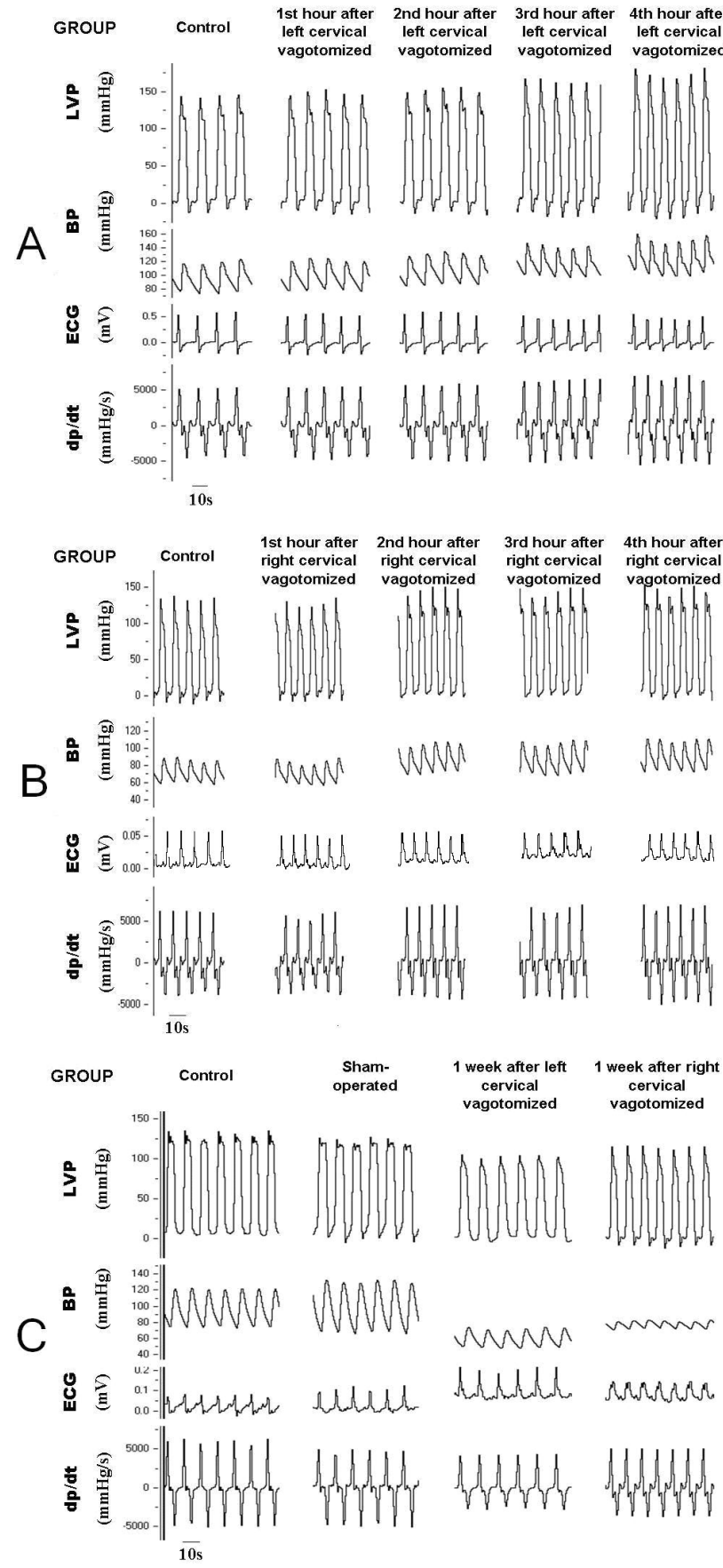

( $\mathrm{p}<0.05$ vs. sham-operated rats), but the density of $\mathrm{M}_{2}$ muscarinic receptors in the right ventricular tissue remained unchanged. Conversely, protein content of $\mathrm{M}_{2}$ muscarinic receptors was increased only in the left atrium and left ventricle one week after right cervical vagotomy ( $<<0.05$ vs. sham-operated rats); the density of receptors did not change in the right atrium and right ventricle.

\section{Cholinesterase-positive nerves in the subacute unilateral vagotomized rat heart}

Histochemical ACh esterase (AChE) staining revealed that cholinesterase-positive nerves were
Fig. 1. Recording examples obtained from the hemodynamic measurements. A: from one rat whose left cervical vagus was sectioned acutely. B: from one rat whose right cervical vagus was sectioned acutely. C: from the different rats in the subacute experiment. Top to bottom for each part, group, left ventricular pressure (LVP), arterial blood pressure (BP), ECG, rate of rise/descend of left ventricular pressure $(\mathrm{dp} / \mathrm{dt})$ and time in seconds. Left to right in $A$ and $B$, represents five time points, including control (before), $1^{\text {st }}$ hour, $2^{\text {nd }}$ hour, $3^{\text {rd }}$ hour and $4^{\text {th }}$ hour after left/right cervical vagotomy. In Figure 1C, Left to right, control, sham-operated, 1 week after left cervical vagotomized and 1 week after right cervical vagotomized group. This figure showed that heart rate (HR), BP, LVP and dp/dt were all increased during the 4 hours after acute left/right cervical vagotomized, however, HR, BP, LVP and $\mathrm{dp} / \mathrm{dt}$ were all decreased in both subacute unilateral cervical vagotomized groups (vs. sham-operated group).

distributed widely in all regions of the rat heart. In the normal intact hearts, there was a larger area of cholinesterase-positive nerves than in the ventricles $(p<0.001)$. The order of distribution of the cholinesterasepositive nerves in rat heart is RA $>$ LA $>$ RV $>$ LV (Fig. 6B). The thick, brown-colored nerves and thin, net-like nerve terminals were visible in the atria. In the ventricles (Fig. 6A), thin nerve fibers running parallel to the longitudinal axis of muscle fibers and occasionally side branches were visible; some of these nerve fibers were ramified.

Significantly more cholin-esterase-positive nerves were visible in $\mathrm{LV}$ and $\mathrm{RV}$ one week after unilateral cervical vagotomy than in the sham-operated group ( $\mathrm{p}<0.05$ or $\mathrm{p}<0.01$ ) (Fig. $6 \mathrm{~B}$ ). When considering the atria, the area of cholinesterase-positive nerves increased only in left atrium following subacute right vagotomy ( $\mathrm{p}<0.05$ compared to sham-operated rats).

\section{Discussion}

Acute unilateral cervical vagotomy increased the HR, BP, LVSP and dp/dt max. Subacute unilateral vagotomy however, reduced the hemodynamic values. In the subacute experiment, $\mathrm{M}_{2}$ muscarinic receptors were upregulated in rat left atria and left ventricles, but in the acute left vagotomized group there was only upregulation in the left atria. The distribution of cholinergic nerves in ventricles increased after subacute unilateral vagotomy and the baroreflex sensitivity increased after right vagotomy. The response of LVSP and $\pm \mathrm{dp} / \mathrm{dt} \max$ to ACh was facilitated in subacutely unilaterally vagotomized rats. Our results suggest that subacute unilateral cervical vagotomy induces contralateral vagus overactivity causing hemodynamic parameters to decrease, upregulating the expression of the $\mathrm{M}_{2}$ muscarinic 

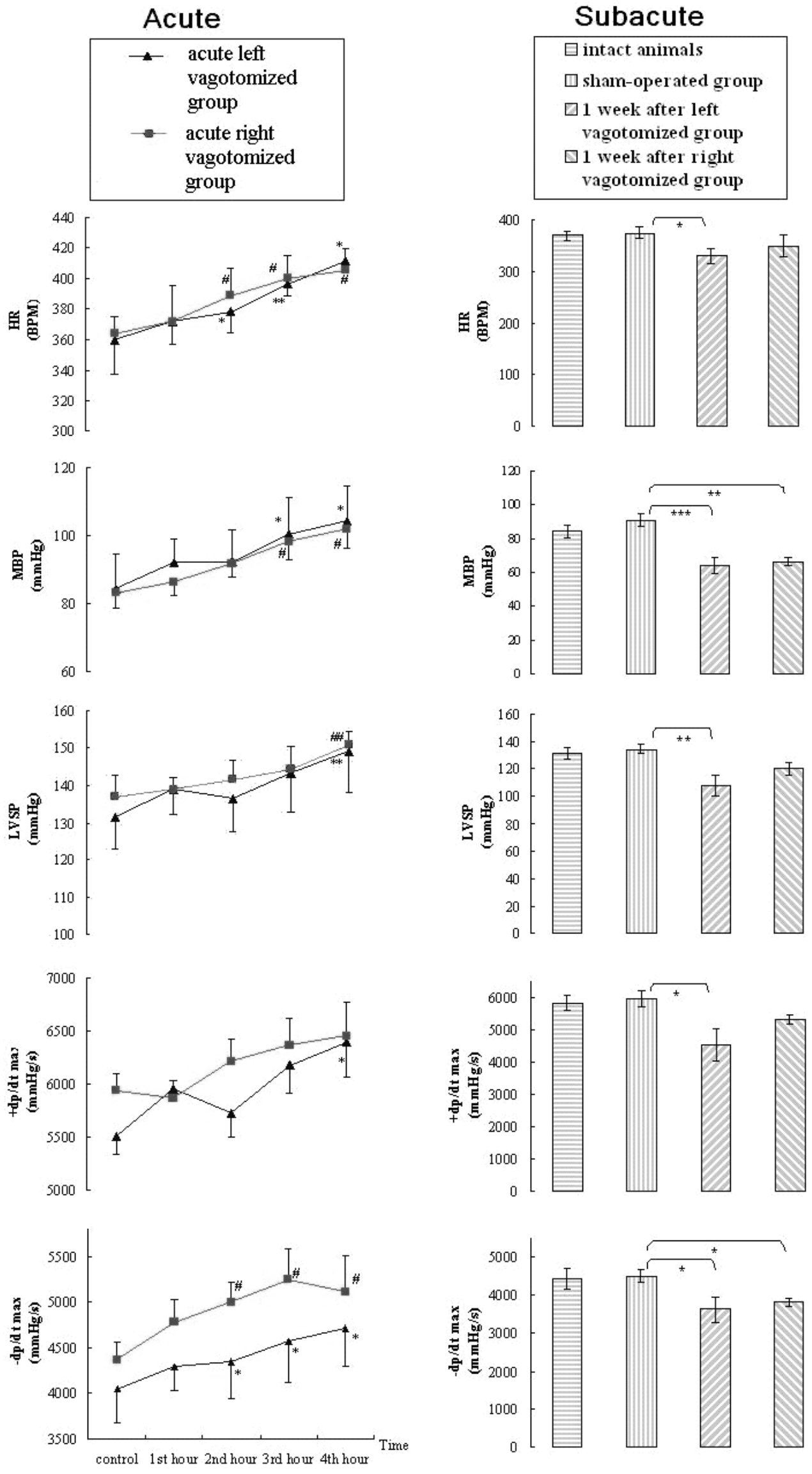

Fig. 2. Influence of acute (left panel) and subacute (right panel) unilateral cervical vagotomy on hemodynamic parameters. Top to bottom for each part is, heart rate (HR), arterial blood pressure (BP), left ventricular pressure (LVP), rate of rise of left ventricular pressure $(+d p / d t)$ and rate of decrease of left ventricular pressure ($\mathrm{dp} / \mathrm{dt}$ ), respectively. The values shown are means \pm S.E.M. $(n=6$ in each acute group; $n=8$ in each subacute group). In the acute part, $*, * *$ represent $\quad \mathrm{p}<0.05$, $\mathrm{p}<0.01$ (acute left cervical vagotomized vs. control); \#, \#\# represent $\quad p<0.05$, $p<0.01$ (acute right cervical vagotomized vs. control), respectively. *, **, *** represent $\mathrm{p}<0.05, \quad \mathrm{p}<0.01$, and $\mathrm{p}<0.01$, respectively, compared with shamoperated rats in the subacute experiment. 

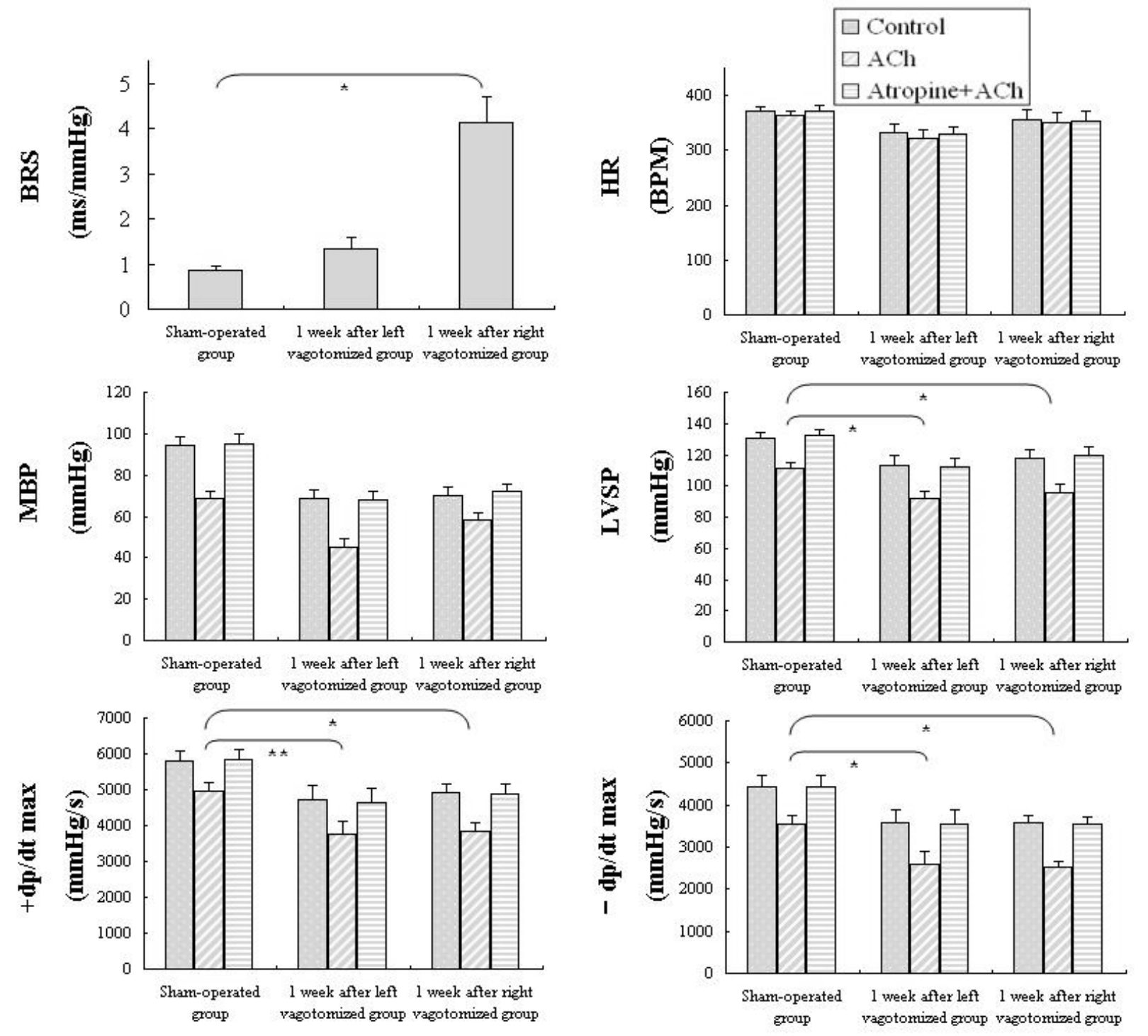

Fig. 3. Baroreflex sensitivity (BRS) and hemodynamic changes of ACh $(0.5 \mu \mathrm{g} / \mathrm{kg})$ after subacute unilateral vagotomy. BRS was quantitated as slope of a line generated from the relationship of $R-R$ interval during increases in arterial pressure. Hemodynamic effects of ACh were detected before or after atropine $(1 \mathrm{mg} / \mathrm{kg})$ treatment. The values shown are means \pm S.E.M. ( $n=8$ in each group). BRS was increase significantly after subacute right vagotomy ( $p<0.05$ vs. sham-operated rats) but not after subacute left vagotomy. The inhibitory effects of ACh on LVSP, $+d p / d t$ max, and $-d p / d t$ max were facilitated evidently after subacute unilateral vagotomy $(p<0.05$ vs. sham-operated rats). The effect of ACh could be blocked completely by atropine. * and ** represent $p<0.05$ and $p<0.01$, compared with sham-operated rats in the subacute experiment.

receptors, mainly on the left side of the heart. Moreover, $\mathrm{M}_{2}$ muscarinic receptor upregulation, the increase in cholinergic nerves and the enhancement of baroreflex sensitivity enhancement may be involved in the mechanism of compensatory recovery of contralateral vagal control of cardiac contractility.

\section{Mechanisms in the compensatory recovery}

In our experiments, acute unilateral vagotomy increased the values of LVSP and dp/dt max, using parameters representing ventricular contractility. HR and
BP also rose with acute partial denervation of the vagus. This result is in agreement with previous studies (Lund et al. 1992, da Silva Soares et al. 2006), and can be explained by an abrupt disruption in the balance between sympathetic and vagal nerves leading to a predominant function of sympathetic nerves in the heart, producing positive chronotropy, dromotropy and inotropy. In line with the changes in hemodynamics, the Western blot results showed that there was little change in the expression of $\mathrm{M}_{2}$ receptors in the heart, with upregulation detected only in the left atria $4 \mathrm{~h}$ after the acute left 
A
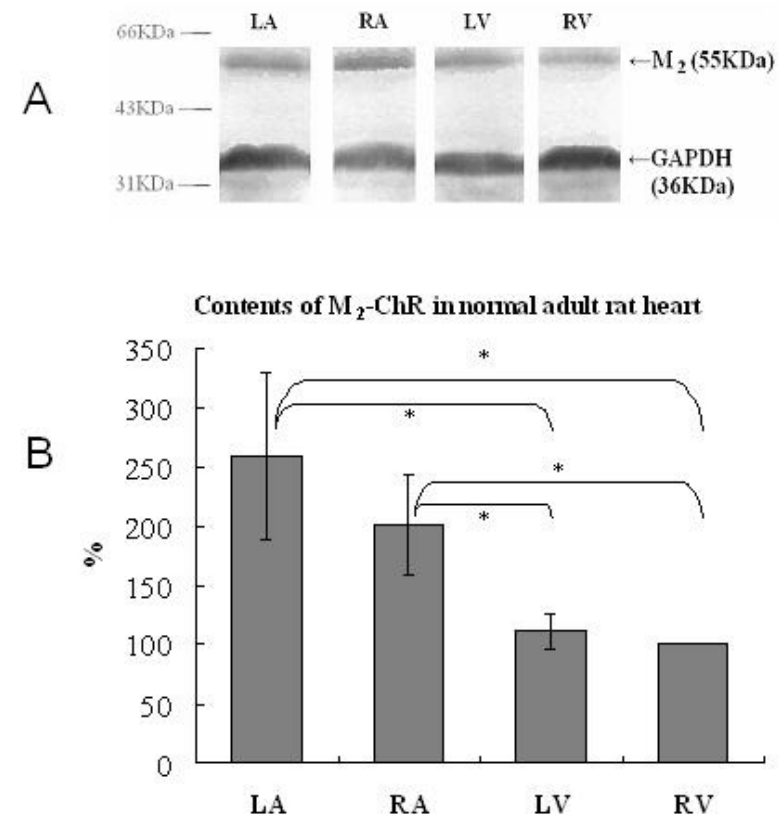

Fig. 4. Expression of the $M_{2}$ receptors in the four chambers of normal adult rat heart. A: Western blots of membrane obtained from rat atria and ventricles. B: the bar plot showing the expression of the $M_{2}$ receptors in the four chambers of normal adult rat heart. LA: left atria; RA: right atria; LV: left ventricles; $\mathrm{RV}$ : right ventricles. The ratio of $\mathrm{OD}\left(\mathrm{M}_{2}\right.$ receptor) / $\mathrm{OD}(\mathrm{GAPDH})$ of RV was used as $100 \%$. The values shown are means \pm S.E.M. ( $n=10$ in each group). * presents $p<0.05$.

vagotomy. The possible reason for this is that receptor regulation maintaining physiological homeostasis is slow.

Several studies showed that HR and BP could return to control levels with chronic ( $>3 \sim 4$ weeks) unilateral vagotomy or partially vagal denervation (Lund et al. 1992, da Silva Soares et al. 2006). We have therefore chosen the subacute experiments to observe this compensatory effect mechanism. In the subacute experiment, hemodynamic parameters including HR, SBP, DBP, MBP, LVSP and $\pm \mathrm{dp} / \mathrm{dt}$ max, all decreased to a different degree after unilateral cervical vagotomy, suggesting that overactive contralateral vagal control may induce cardiac function inhibition. This may be termed compensatory recovery via contralateral vagal regulation (Lund et al. 1992). These results are consistent with the hypothesis that intact parasympathetic neurons compensate for denervation following unilateral vagotomy (Brown 1981).

It is generally believed that when nerves are damaged, new synaptic connections or recollateralization may occur via collateral branches from remaining nerve tissue. There is evidence, that in frogs an intact vagus nerve can produce new synaptic connections to cardiac ganglion cells, when their original synaptic input is disrupted by means of unilateral vagotomy (Courtney and Roper 1976). Mammalian studies in electrophysiology and neurochemistry also support the concept of the compensatory recovery of cardiac vagal innervation after unilateral vagotomy in rats, guinea-pigs (Lund et al. 1979), cats (Brown 1981) and rabbits (Lund et al. 1992). The present histological staining showed that the area of the cholinesterase-positive nerves in left ventricle and right ventricle increased after subacute unilateral vagotomy, suggesting that cholinergic-nerve fibre recollateralization in the rat ventricles might be involved in the compensatory recovery of ventricular contractility.

It is well known that sprouting (Courtney and Roper 1976, Lund et al. 1992) is the main reason for the compensatory restoration of contralateral vagal control and reestablishment of synaptic connections interrupted by a preceding contralateral vagotomy. Reorganization of the central components of the cardiac parasympathetic system (Helke et al. 1983) is also involved in this process. Baroreflex sensitivity increase could also take part in the compensatory changes (Lund et al. 1992, da Silva Soares et al. 2006). Our result showed that the baroreceptor reflex response increased after subacute right vagotomy, which also supported the role of the central components in compensatory recovery.

It remains controversial whether metabolic changes, such as a decrease in choline acetyltransferase (CAT) activity, follow the same mechanism. Lund et al. (1979) demonstrated that, in rats there was a transient decrease in CAT activity in the region of the SA nodes within $72 \mathrm{~h}$ of a unilateral vagotomy, but beyond $72 \mathrm{~h}$ there was no change compared with the control. However, their later study discounted changes in neuroeffector responsiveness to cholinergic stimulation or the metabolic fate of acetylcholine as contributing factors to the compensatory changes in vagal control of heart rate after unilateral vagotomy (Lund et al. 1992).

The role of the muscarinic receptors in the compensatory effects after partial loss of vagal innervation is unclear. Lund et al. (1992) showed no change in the responsiveness of the heart rate to methacholine or in the effects of physostigmine after right vagotomy in rabbits. However, this study excluded the influence of acetylcholine, which may increase during stimulation of one vagal trunk after interruption of the contralateral vagal trunk. In our experiment, the inhibitory effect of ACh on heart rate was not changed, but the decreasing ventricular contractility of ACh was facilitated after unilateral vagotomy. Meanwhile, the 
expression of $\mathrm{M}_{2}$ receptors increased specifically in the left ventricle after subacute unilateral vagotomy. This suggests that $\mathrm{M}_{2}$ muscarinic receptor upregulation might be involved in the mechanism of the compensatory recovery of contralateral vagal control of cardiac contractility. The density of muscarinic receptors in dog ventricles was increased, and the electrophysiologic responses to $\mathrm{ACh}$ in ventricular myocyte were more sensitive following parasympathectomy (Hodges et al. 1989), which is in line with the role of muscarinic receptor. In addition, guanine nucleotide might be partly involved in compensatory recovery (Hodges et al. 1989).

The combination of results from our hemodynamic evaluations, Western blot analyses, and cholinesterase-positive nerves staining suggests that the upregulation of $\mathrm{M}_{2}$ muscarinic receptors, the increase in cholinergic-nerves, and the high baroreflex sensitivity could contribute to the mechanism of compensatory recovery of hemodynamic function. This is secondary to contralateral vagus overactivity, with increased receptors amplifying contralateral vagal activity and decreasing cardiac contractility.

\section{Cholinergic nerves and muscarinic receptors in different regions of the heart}

The distribution of muscarinic receptors and cholinergic innervation overlapped in rat cardiac parasympathetic ganglia, nodal tissue, His bundlePurkinje system, vena cava and pulmonary veins (Hancock et al. 1987). Cholinergic innervation to the right atrium was greater than innervation to the left atrium, while innervation of the ventricles was confined primarily to the base of the right ventricle (Hancock et al. 1987). Positive staining of cholinergic nerves was found in all regions of the rat heart, and the point count of cholinergic nerves in the atria was 4.6 times greater than in the ventricles ( $\mathrm{Xu}$ et al. 2006). Our result is in agreement with these findings. Acetylcholinesterase (AChE) is not a selective marker for cholinergic neurons, so AChE histochemistry may overestimate the density of cholinergic innervation in the heart (Hoover et al. 2004).

In radioligand-binding studies, the atrial regions of rabbit, rat (Fields et al. 1978, Hancock et al. 1987), chick (Sorota et al. 1986), and human (Deighton et al. 1990, Mittmann et al. 2003) hearts showed a higher density of muscarinic receptors compared to ventricular myocardium. The density of receptor binding in these species was similar in right and left atria and, likewise, for right and left ventricles. Furthermore, muscarinic receptors were also detected in guinea pig (Leon-Velarde et al. 1998) and canine ventricles (Yang et al. 1992). In our laboratory, species differences in $M$ receptors distribution in the heart have been observed (Zeng et al. 2005). For example, the density of $\mathrm{M}$ receptors is significantly higher in the atria (up to 3 -fold in rats; up to 1.5 -fold in guinea-pigs; and up to 3.5 -fold in rabbits) than in the ventricles. However, nonselective radioligand has a limitation because it is able to bind the different subtypes of muscarinic receptors, while immunobinding can selectively bind to a special subtype receptor.

$\mathrm{M}_{2}$ receptor is the predominant type in the heart (Sharma et al. 1997, Wang et al. 2001), although there might also exist $\mathrm{M}_{1}, \mathrm{M}_{3}$, and $\mathrm{M}_{4}$ receptors (Wang et al. 2004). Regional differences exist for the distribution of $\mathrm{M}_{2}$-receptors in the human heart: the number of $\mathrm{M}_{2}$ receptors is significantly greater in the atria (up to 2.5 -fold) than in the ventricular myocardium (Deighton $e t$ al. 1990, Giessler et al. 1999, Wang et al. 2001). Our Western blot results also demonstrate that $\mathrm{M}_{2}$ receptors are expressed in rat left and right ventricles, although not at the same density as in the atria (where densities are up to 2 2.6-fold higher).

\section{Vagal control of ventricular contractility}

There is a common misconception that the sympathetic nerves innervate the entire heart, while the parasympathetic nerves only innervate supraventricularly, since vagal fibres are rarely found in the ventricles, and muscarinic agonists have little or no effect on ventricular function under basal conditions (Brodde and Leineweber 2004, Harvey and Belevych 2003, Levy and Warner 1994). Recent evidence indicates that the cholinergic innervation of the left ventricle is functionally very important in some mammalian species (Zang et al. 2005a). Electrical stimulation of the vagus nerves of the left ventricular myocardium in the cat caused an increased release of acetylcholine (Akiyama and Yamazaki 2001), and reduced the contractility of the left ventricle in the dog (Levy and Warner 1994, Xenopolous and Applegate 1994), pig and human (Casadei 2001, Lewis et al. 2001). Indirect inotropy of vagal stimulation and muscarinic agonists are well known and a direct inotropic effect exists in the ferret, rat, guinea-pig, and human ventricles (Zang et al. 2005a).

Parameters that reflect cardiac contractility (such as LVSP, $+\mathrm{dp} / \mathrm{dt} \max$ ) were decreased after subacute left vagotomy. By Western blot analysis, the expression of $\mathrm{M}_{2}$ muscarinic receptors was observed to increase in the 


\section{Acute}

LA

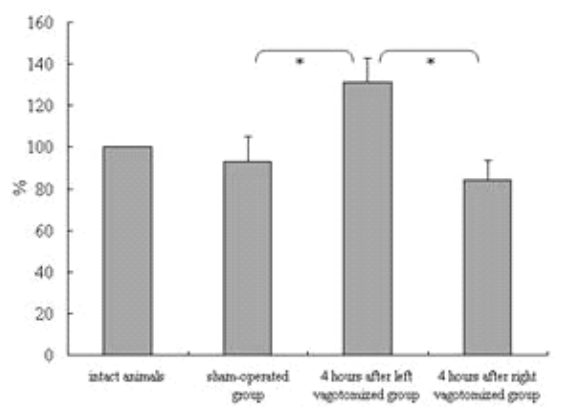

RA

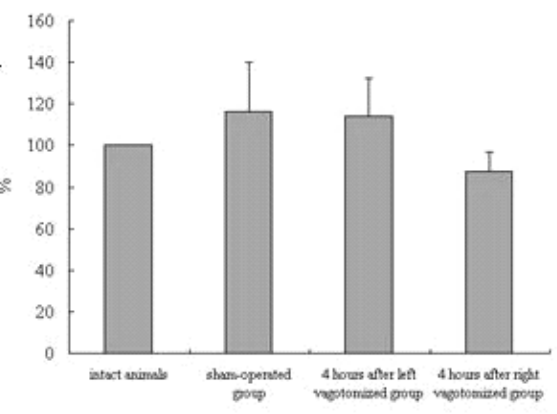

LV
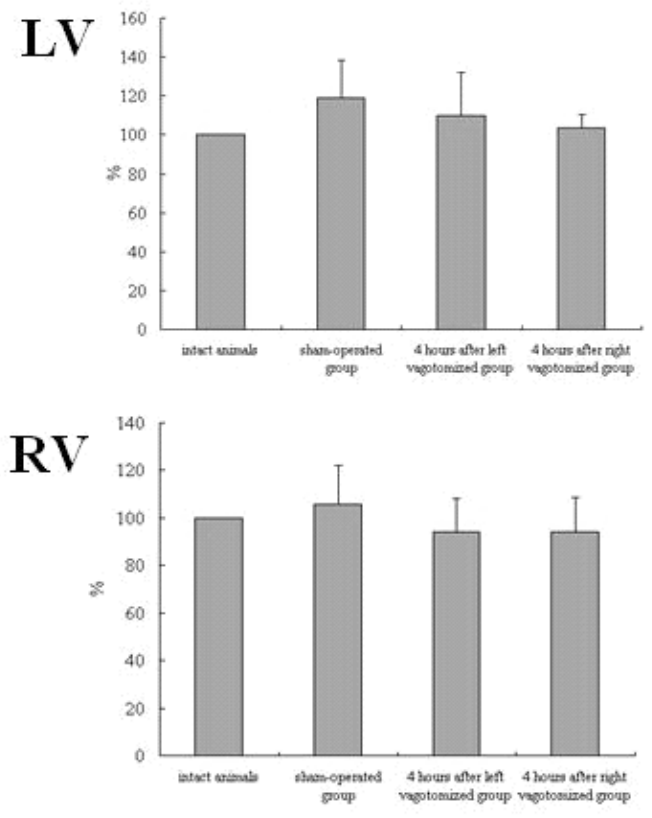

Subacute
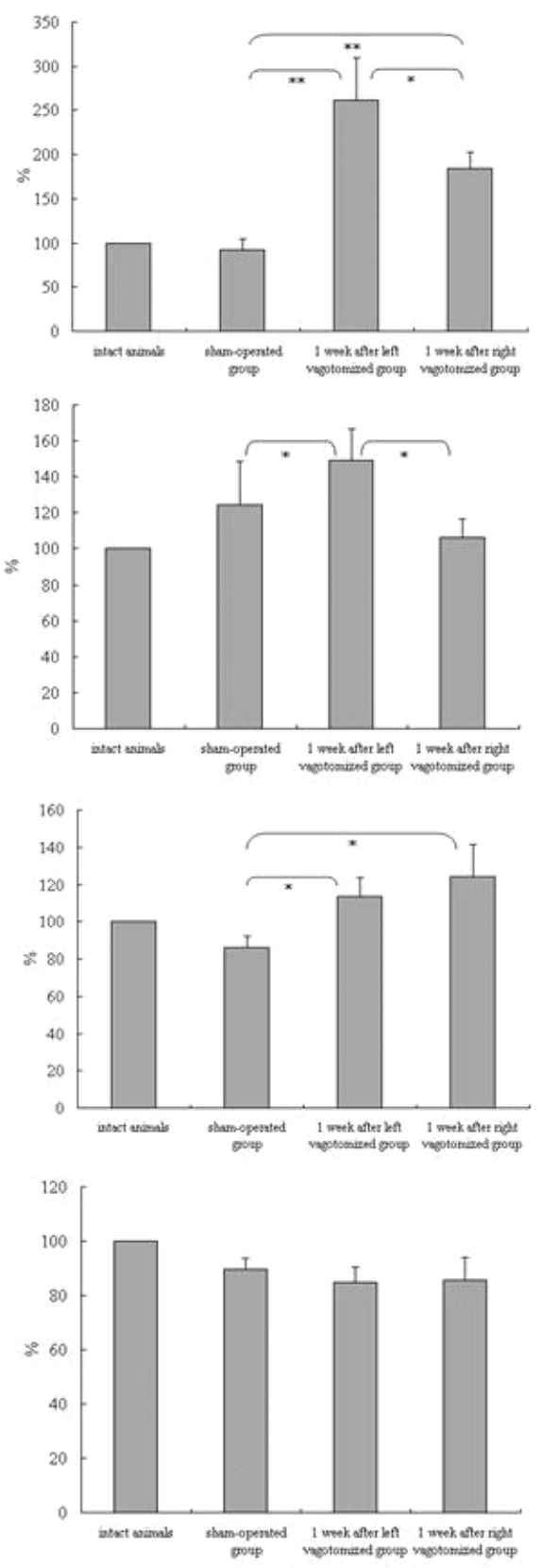

Fig. 5. Influence of acute and subacute unilateral vagotomy on the expression of $M_{2}$ receptor in the 4 chambers of the rat hearts. Ordinate: the content of $M_{2}$ receptor expressed with the percentage to the control group. The ratio of OD ( $M_{2}$ receptor) / OD (GAPDH) of the control group was used as $100 \%$. Abscissa in left (acute) part: the groups including intact animals $(n=8)$, sham-operated ( $n=6)$, 4 hours after left /right cervical vagotomized group ( $n=6$ in either group); abscissa in right (subacute) part: the groups including intact animals, sham-operated, one week after left /right cervical vagotomized group ( $n=8$ in each group). LA: left atria; RA: right atria; LV: left ventricles; RV: right ventricles. The values shown are means \pm S.E.M. ${ }^{*}$ and $* *$ represent $p<0.05$ and $p<0.01$, compared with sham-operated rats.

atria and the left ventricle, but not in the right ventricle one week after left cervical vagotomy. This suggests that the response of the contralateral vagus and the changes in $\mathrm{M}_{2}$-receptors in rat heart are more sensitive to left cervical vagotomy. HR also decreased one week after left cervical vagotomy, which is consistent with a previously reported study in rabbits (Lund et al. 1992). The phenomenon may reflect the possibility that the SA node is predominantly innervated by the right vagus. In addition, it suggests that the right cervical vagus nerve's over-activity after left cervical vagotomy may play a more important role in cardiac contraction and that the 


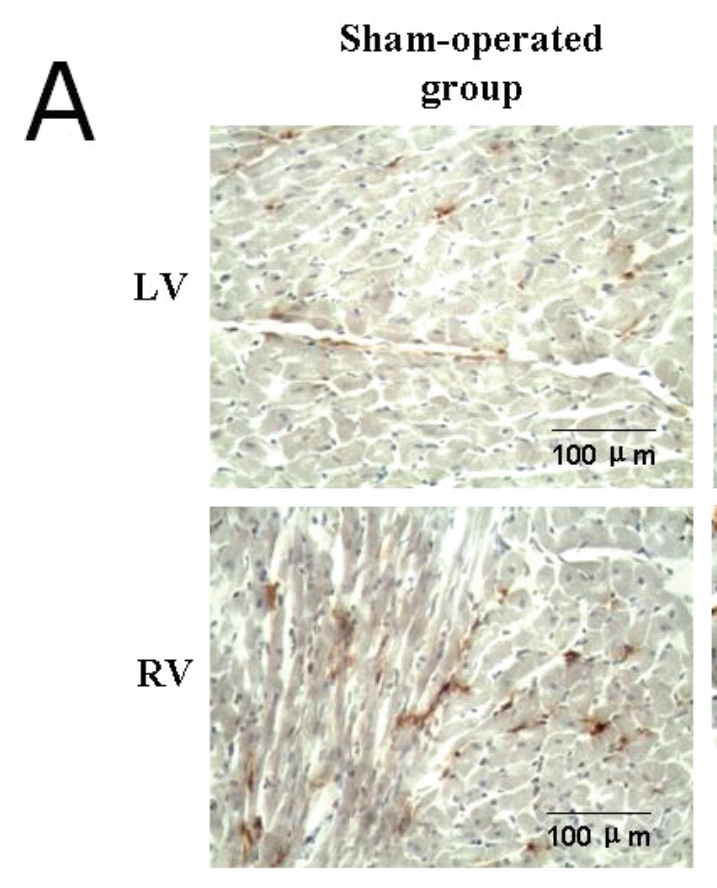

\section{1 week after left vagotomized group}
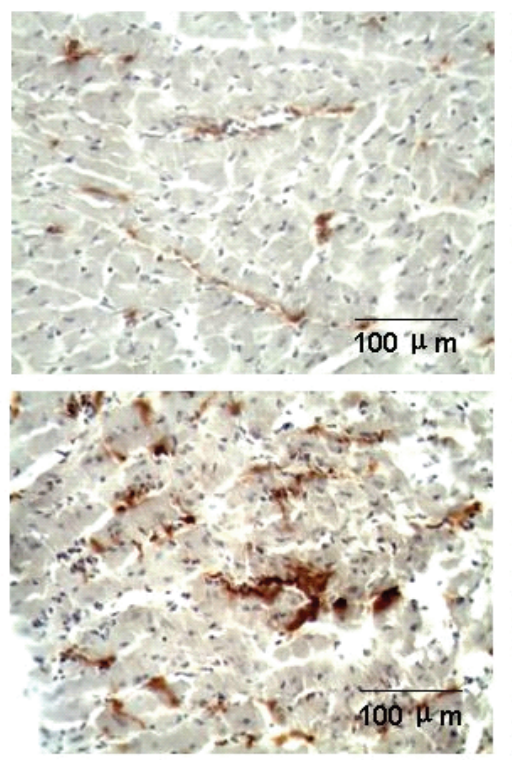

1 week after right

vagotomized group

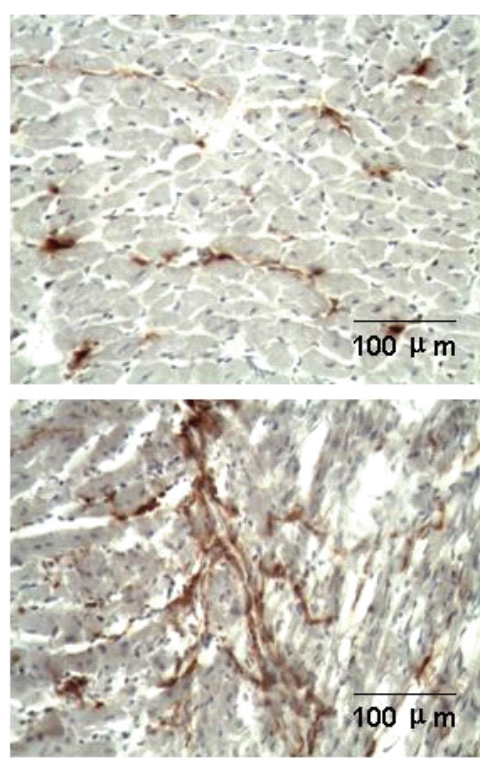

B

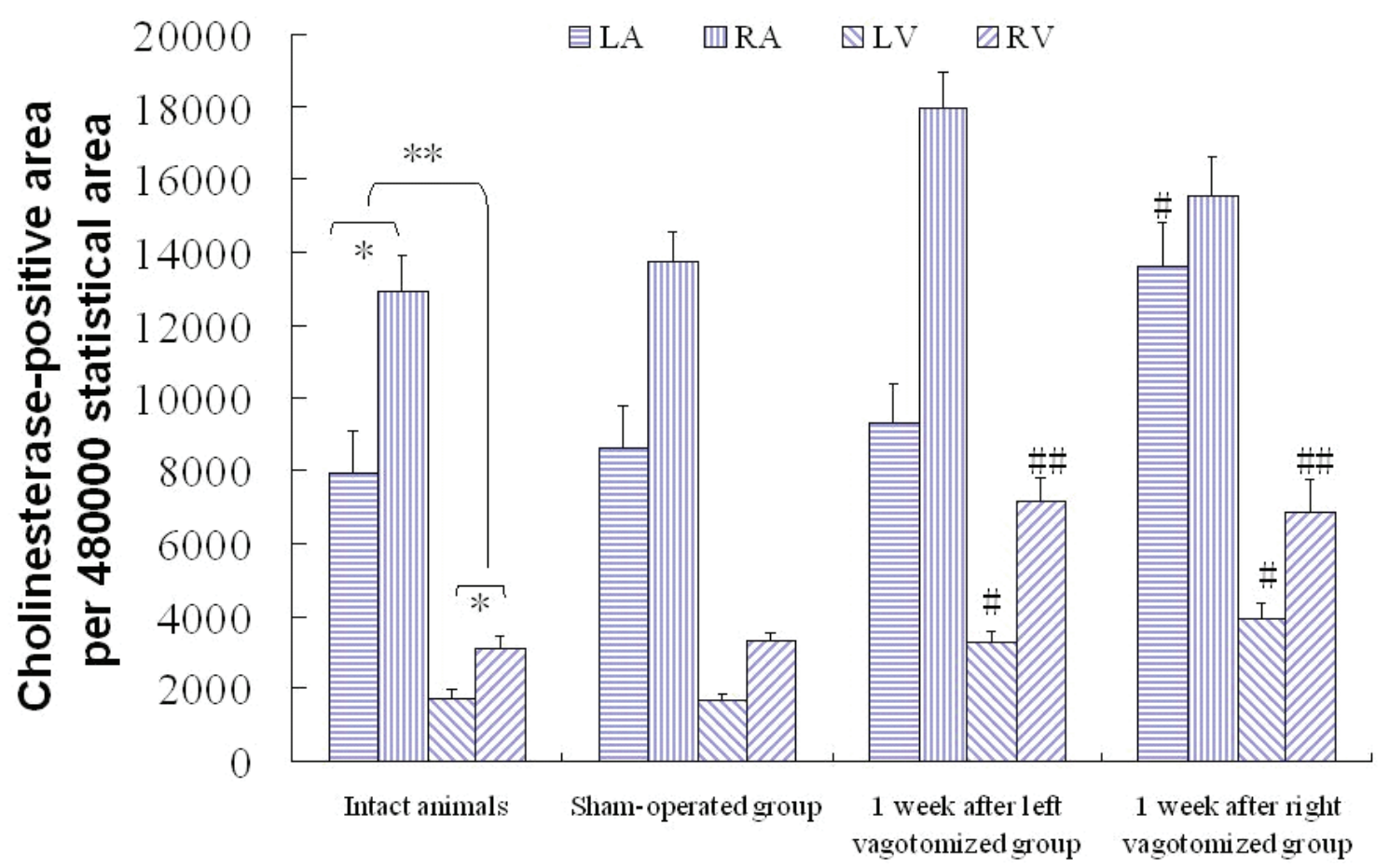

Fig. 6. A: Photomicrographs of staining for cholinesterase-positive nerves of rat left ventricle (upper row) and right ventricle (lower row) from the sham-operated, 1 week after left vagotomized and 1 week after right vagotomized rats. B: Distribution of cholinesterasepositive nerves in the subacute unilateral cervical vagotomized rat heart. Ordinate: the whole area of cholinesterase-positive nerves per 480000 statistical area. LA: left atria; RA: right atria; LV: left ventricles; RV: right ventricles. The values shown are means \pm S.E.M. $n=8$ in each group. ${ }^{*}$ and $* *$ represent $p<0.05$ and $p<0.01$. \# $p<0.05, \# \# p<0.01$, compared with sham-operated rats.

left vagus may have a greater basal role than the right one. Our results indicate that the $\mathrm{M}_{2}$ muscarinic receptors in the left part of rat heart might react more sensitively to vagal denervation, especially after left cervical vagotomy.

A previous study (Kovach et al. 1995) demonstrated that each vagus nerve contributes approximately equally to the tonically-dilated state of the dog's epicardial coronary arteries, again documenting that both the left and right vagus nerves play an important role in cardiac ventricular function, especially in terms of 
cardiac contractility. Despite earlier inotropic studies which suggest that ventricular tissue receives an overlapping projection from both the right and left vagal nerves, the regional predominance of the right or left vagus remains unclear in the ventricle (Kawano et al. 2003).

Our data prove that the left and right cervical vagus have overlapping innervation, not only in the atria but also in the ventricles, suggesting that rat ventricular tissue may also receive overlapping innervation from the right and left vagus nerves (Akiyama and Yamazaki 2001) in a similar manner to canine hearts (Sitdikov et al. 2000). However, the difference in the influence of left/ right cervical vagotomy obtained from our experiments supports an asymmetrical vagal innervation in different regions of the heart, although there are several areas of vagus nerve overlap.

In conclusion, our present experiments indicate, that the working myocardium is innervated bilaterally by the vagus; that ventricular contractility is influenced more by denervation of the left vagus than the right; and that upregulation of $\mathrm{M}_{2}$ muscarinic receptors in the left heart, increase of cholinergic nerves, and high baroreflex sensitivity could be involved in the mechanism of compensatory hemodynamic recovery via contralateral vagus overactivity, thereby amplifying contralateral vagal activity and decreasing cardiac contractility.

\section{Conflict of Interest}

There is no conflict of interest.

\section{Acknowledgements}

This work was supported by grants from the National Basic Research Program of China (973 Program) (No. 2007CB512005), the National Natural Science Foundation of China (Nos. 30470633, 30770785), the Cultivation Fund of the Key Scientific and Technical Innovation Project of Chinese Ministry of Education (No. 705045), the Specialized Research Fund for the Doctoral Program of Higher Education (No. 20050698012), the Natural Science Foundation of Shaanxi Province (2005C234), and the Doctorial Foundation of Xi'an Jiaotong University (No. 2003-13) of China.

\section{References}

AKIYAMA T, YAMAZAKI T: Effects of right and left vagal stimulation on left ventricular acetylcholine levels in the cat. Acta Physiol Scand 172: 11-16, 2001.

ANGELL-JAMES JE, GEORGE MJ, PETERS CJ: Baroreflex sensitivity in rabbits during the development of experimental renal hypertension and medial sclerosis. Clin Exp Hypertens 2: 321-340, 1980.

BRODDE OE, LEINEWEBER K: Autonomic receptor systems in the failing and aging human heart: similarities and differences. Eur J Pharmacol 500: 167-176, 2004.

BROWN OM: Cat heart acetylcholine: unilateral vagotomy studies with pyrolysis-mass fragmentography. Life Sci 28: 819-825, 1981.

CASADEI B: Vagal control of myocardial contractility in humans. Exp Physiol 86: 817-823, 2001.

COURTNEY K, ROPER S: Sprouting of synapses after partial denervation of frog cardiac ganglion. Nature 259: $317-$ 319, 1976.

DA SILVA SOARES PP, PORTO CS, ABDALlA FM, DE LA FUENTE RN, MOREIRA ED, KRIEGER EM, IRIGOYEN MC: Effects of rat sinoaortic denervation on the vagal responsiveness and expression of muscarinic acetylcholine receptors. J Cardiovasc Pharmacol 47: 331-336, 2006.

DEIGHTON NM, MOTOMURA S, BORQUEZ D, ZERKOWSKI HR, DOETSCH N, BRODDE OE: Muscarinic cholinoceptors in the human heart: demonstration, subclassification, and distribution. Naunyn Schmiedebergs Arch Pharmacol 341: 14-21, 1990.

DHEIN S, VAN KOPPEN CJ, BRODDE OE: Muscarinic receptors in the mammalian heart. Pharmacol Res 44: 161$182,2001$.

FIELDS JZ, ROESKE WR, MORKIN E, YAMAMURA HI: Cardiac muscarinic cholinergic receptors. Biochemical identification and characterization. J Biol Chem 253: 3251-3258, 1978.

GIESSLER C, DHEIN S, PONICKE K, BRODDE OE: Muscarinic receptors in the failing human heart. Eur $J$ Pharmacol 375: 197-202, 1999. 
HANCOCK JC, HOOVER DB, HOUGLAND MW: Distribution of muscarinic receptors and acetylcholinesterase in the rat heart. J Auton Nerv Syst 19: 59-66, 1987.

HARVEY RD, BELEVYCH AE: Muscarinic regulation of cardiac ion channels. Br J Pharmacol 139: 1074-1084, 2003.

HELKE CJ, HANDELMANN GE, JACOBOWITZ DM: Choline acetyltransferase activity in the nucleus tractus solitarius: regulation by the afferent vagus nerve. Brain Res Bull 10: 433-436, 1983.

HODGES TD, BAILEY JC, FLEMING JW, KOVACS RJ: Selective parasympathectomy increases the quantity of inhibitory guanine nucleotide-binding proteins in canine cardiac ventricle. Mol Pharmacol 36: 72-77, 1989.

HOOVER DB, GANOTE CE, FERGUSON SM, BLAKELY RD, PARSONS RL: Localization of cholinergic innervation in guinea pig heart by immunohistochemistry for high-affinity choline transporters. Cardiovasc Res 62: 112-121, 2004.

KARNOVSKY MJ, ROOTS LA: A “direct-coloring” thiocholine method for cholinesterase. J Histochem Cytochem 12: 219-221, 1964.

KAWANO H, OKADA R, YANO K: Histological study on the distribution of autonomic nerves in the human heart. Heart Vessels 18: 32-39, 2003.

KOVACH JA, GOTTDIENER JS, VERRIER RL: Vagal modulation of epicardial coronary artery size in dogs. A twodimensional intravascular ultrasound study. Circulation 92: 2291-2298, 1995.

LEON-VELARDE F, RICHALET JP, CHAVEZ JC, KACIMI R, RIVERA-CHIRA M, PALACIOS JA , CLARK D : Inter and intra-species-related differences in the regulation of the cardiac autonomic system. Comp Biochem Physiol B Biochem Mol Biol 119: 819-823, 1998.

LEVY MN, WARNER MR: Parasympathetic effects on cardiac function. In: Neurocardiology. JA ARMOUR, JL ARDELL (eds), Oxford Univ Press, New York, 1994, pp 53-76.

LEWIS ME, AL-KHALIDI AH, BONSOR RS, CLUTTON-BROCK T, MORTON D, PATERSON D, TOWNEND $\mathrm{JN}$, COOTE JH: Vagus nerve stimulation decreases left ventricular contractility in vivo in the human and pig heart. J Physiol Lond 534: 547-552, 2001.

LOFFELHOLZ K, PAPPANO AJ: The parasympathetic neuroeffector junction of the heart. Pharmacol Rev 37: 1-24, 1985.

LUND DD, SCHMID PG, ROSKOSKI RJr: Choline acetyltransferase activity in rat and guinea pig heart following vagotomy. Am J Physiol 236: H620-H623, 1979.

LUND DD, DAVEY GA, SUBIETA AR, PARDINI BJ: Compensatory recovery of parasympathetic control of heart rate after unilateral vagotomy in rabbits. Am J Physiol 262: H1122-H1127, 1992.

MITTMANN C, PINKEPANK G, STAMATELOPOULOU S, WIELAND T, NURNBERG B, HIRT S, ESCHENHAGEN T: Differential coupling of m-cholinoceptors to Gi/Go-proteins in failing human myocardium. J Mol Cell Cardiol 35: 1241-1249, 2003.

NEELY BH, URTHALER F: Quantitative effects of sympathetic and vagal nerve stimulations on sinus and AV junctional rhythms. J Auton Nerv Syst 37: 109-120, 1992.

ROPER S: Sprouting and regeneration of synaptic terminals in the frog cardiac ganglion. Nature 261: 148-149, 1976.

SAMPAIO KN, MAUAD H, SPYER KM, FORD TW:. Differential chronotropic and dromotropic responses to focal stimulation of cardiac vagal ganglia in the rat. Exp Physiol 88: 315-327, 2003.

SHARMA VK, COLECRAFT HM, RUBIN LE, SHEU SS: Does mammalian heart contain only the $\mathrm{M}_{2}$ muscarinic receptor subtype? Life Sci 60: 1023-1029, 1997.

SIEGEL GJ, AGRANOFF BW, ALBERS RW, FISHER SK, UHLER MD: Basic Neurochemistry, Molecular, Cellular and Medical Aspects. Lippincott, Williams and Wilkins, Philadelphia. 1999.

SITDIKOV FG, GIL'MUTDINOVA RI, MINNAKHMETOV RR, ZEFIROV TL: Asymmetrical effects of vagus nerves on functional parameters of rat heart in postnatal ontogeny. Bull Exp Biol Med 130: 620-623, 2000.

SOROTA S, ADAM LP, PAPPANO AJ: Comparison of muscarinic receptor properties in hatched chick heart atrium and ventricle. $J$ Pharmacol Exp Ther 236: 602-609, 1986.

TAYEBATI SK, DI TULLIO MA, AMENTA F: Age-related changes of muscarinic cholinergic receptor subtypes in the striatum of Fisher 344 rats. Exp Gerontol 39: 217-223, 2004. 
WANG H, HAN H, ZHANG L, SHI H, SCHRAM G, NATTEL S, WANG Z: Expression of multiple subtypes of muscarinic receptors and cellular distribution in the human heart. Mol Pharmacol 59: 1029-1036, 2001.

WANG Z, SHI H, WANG H: Functional $\mathrm{M}_{3}$ muscarinic acetylcholine receptors in mammalian hearts. Br J Pharmacol 142: 395- 408, 2004.

WITTLING W, BLOCK A, GENZEL S, SCHWEIGER E: Hemisphere asymmetry in parasympathetic control of the heart. Neuropsychology 36: 461-468, 1998.

XENOPOLOUS NP, APPLEGATE RJ: The effect of vagal stimulation on left ventricular systolic and diastolic performance. Am J Physiol 266: H2167-H2173, 1994.

XU XL, ZANG WJ, LU J, KANG XQ, LI M, YU XJ: Effects of carvedilol on $\mathrm{M}_{2}$ receptors and cholinesterase-positive nerves in adriamycin-induced rat failing heart. Auton Neurosci 130: 6-16, 2006.

YANG CM, YEH HM, SUNG TC, CHEN FF, WANG YY: Characterization of muscarinic receptor subtypes in canine left ventricular membranes. J Recept Res 12: 427-449, 1992.

ZANG WJ, CHEN LN, YU XJ: Progress in the study of vagal control of cardiac ventricle. Acta Physiol Sin 57: 659$672,2005 \mathrm{a}$.

ZANG WJ, CHEN LN, YU XJ, FANG P, LU J, SUN Q: Comparison of acetylcholine on electromechanical characteristics of guinea-pig atrium and ventricle. Exp Physiol 90: 123-130, $2005 \mathrm{~b}$.

ZENG JR, ZANG WJ, LIN YX, YU XJ, CHEN LN, KANG XQ, LU J: The comparison of M acetylcholine receptors in atrial and ventricular myocardium of rats, guinea pig and rabbits. (in Chinese) Chin Heart J 17: 210-212, 2005. 